\title{
Binocular rivalry occurs without simultaneous presentation of rival stimuli
}

\author{
ROBERT P. O'SHEA and BORIS CRASSINI \\ University of Queensland, St. Lucia, Australia
}

\begin{abstract}
It has always been assumed that for binocular rivalry to occur, the dichoptic stimuli must be exposed simultaneously. However, we demonstrate binocular rivalry between rival stimuli that are never simultaneously displayed. This successive binocular rivalry is indistinguishable from normal rivalry with equal-duration alternate presentation of the rival stimuli at rates down to about $20 \mathrm{~Hz}$. Rivalry is evident despite obvious flicker for presentation rates as low as $3 \mathrm{~Hz}$. Rivalry also survives a dark interval of more than $100 \mathrm{msec}$, introduced between alternate brief presentations ( $5 \mathrm{msec}$ ) of the dichoptic stimuli. Simultaneous brief exposure of the rival stimuli produces an equivalent amount of rivalry, which persists for more than $300 \mathrm{msec}$. This implies that rivalry persistence involves a peripheral, monocular component and a central, binocular component, as has been shown for stereopsis.
\end{abstract}

The phenomenon of binocular contour rivalry was first reported by Wheatstone in 1838 :

[If the capital letters $S$ and $A$, each enclosed by a circular boundary,] are presented at the same time [italics added] to a different eye, the common border will remain constant, while the letter in it will change alternately from that which would be perceived by the right eye alone to that which would be perceived by the left eye alone. At the moment of change the letter which has just been seen breaks into fragments, while fragments of the letter which is about to appear mingle with them, and are immediately after replaced by the entire letter (Wheatstone, 1852, p. 259).

Since that report, numerous studies have attempted to explain rivalry, concentrating on attributes of the observers (such as personality, attention, arousal) and on spatial aspects of the rival stimuli (such as orientation, contrast, spatial frequency) (Walker, 1978). However, Wheatstone's assumption that rival stimuli must be present "at the same time" has not, to our knowledge been systematically investigated. In this paper, we demonstrate that binocular rivalry, essentially indistinguishable from what may be termed classical or simultaneous rivalry, can be produced when rival dichoptic stimuli are never presented simultaneously. We term this successive binocular rivalry, and suggest that the phenomenon has relevance for the study of visual persistence, as well

A brief report of these experiments was presented at the Fifteenth Annual Conference of the Australian Psychological Society, Darling Downs Institute of Advanced Education, Toowoomba, Australia, 24-29 August, 1980. We thank Dae Sharrock for her forbearance in what was a very taxing series of 14 observational sessions. Address reprint requests to Robert P. O'Shea, Department of Psychology, Queen's University, Kingston, Ontario, Canada K7L 3N6. as for the study of processes underlying binocular rivalry and its relation to stereopsis.

A number of people have employed alternate dichoptic presentation of rival stimuli, but for purposes other than exploring rivalry. Sherrington (1904) described rivalry between uncontoured fields differing in luminance when these were alternated at unspecified rates. Werner (1940) mentioned binocular rivalry between a ring and a disk with alternate exposures separated by less than about $50 \mathrm{msec}$. As a control condition in an investigation of integration of movement, Clarke (1977) presented to one eye a visual noise field moving in one direction and alternately one moving in the opposite direction. He noted that binocular rivalry resulted. Much longer exposures and ISIs have been used. Klüver (1926) found one observer who gave binocular-rivalrylike reports when an eidetic image of a contour originally shown to one eye was superimposed on a rival contour presented to the other. The most common finding with these uncommon observers is that the eidetic image is suppressed (see also Stromeyer, 1970).

Alexander and Berman (1976) examined the influence, on rivalry, of viewing the stimuli through a sectored disk rotating at an unspecified rate. From the geometry of the sectors, it is possible that subjects received alternate presentation of the rival stimuli, depending on the position of their eyes relative to the center of the disk. What is more likely is that both stimuli were visible simultaneously but intermittently. Rivalry rate when viewing through the rotating disk was not different from that with continuous illumination.

Dawson (1915-1917) was apparently the first to investigate the influence on rivalry of simultaneously but intermittently illuminating both rival stimuli. He observed that "when the eyes were opened and closed rapidly, both sets of [rival] lines were seen simultaneously forming a network of squares" (p. 537). 
This is an almost identical description to that given by Kaufman (1963), who controlled the stimuli with more precision by using a strobe lamp. His rival display consisted of gratings of orthogonal lines illuminated for $50 \mathrm{msec}$ at $2 \mathrm{~Hz}$ with a $210,000-1 \mathrm{x}$ source. Under these circumstances, Kaufman's subjects "said that they saw either a grid, as in graph paper, or a black field filled with white squares" (p. 412). With normal room lighting, all subjects reported rivalry. Unfortunately, both these studies use problematic methodologies. Blinking is thought to involve a suppression akin to saccadic suppression (Riggs, Volkmann, \& Moore, 1981), which could have determined perception. Kaufman confounded the temporal characteristics of the lighting with its level. The room lighting would undoubtedly be considerably dimmer than $210,0001 x$. Wolfe (1983) brought more methodological rigor to bear by testing for rivalry over a wide range of stimulus durations, interstimulus intervals (ISIs), luminances, and spatial frequencies. He confirmed Kaufman's finding and termed the percept "abnormal fusion." This was maximized with brief illumination (less than $150 \mathrm{msec}$ ) and longer ISIs. With shorter dark intervals, rivalry was observed.

A different approach has been to present rival stimuli simultaneously in a single flash. With presentations less than about $500 \mathrm{msec}$, subjects would find it difficult to say whether there had been any conventional rivalry (which consists of dominance periods lasting for about $1 \mathrm{sec}$ ). So investigators have asked subjects to say whether one or both rival stimuli are visible, and, if both, whether they look like an optical superimposition (abnormal fusion) or piecemeal suppression. The most recent evidence shows that the percept depends on the duration of the stimuli. Wolfe (1983) found fusion for durations of less than $150 \mathrm{msec}$ and rivalry for longer presentations. His more precise summary is generally consistent with earlier work (Anderson, Bechtoldt, \& Dunlap, 1978; Bokander, 1966; Bower \& Haley, 1964; Goldstein, 1970).

Wolfe (1983) assumes that eye-of-origin (utrocular) information is lost at the durations allowing abnormal fusion. As stereopsis is preserved with such brief presensations, he argues that rivalry and stereopsis must be independent. This does not necessarily follow. Utrocular information could be retained, or dealt with automatically by the stereopsis mechanism (Blake \& Cormack, 1979). Also, while stereopsis and rivalry can coexist, rivalry has been found to inhibit perceived depth (Hochberg, 1964, 1965; Levy \& Lawson, 1978), and to be inhibited by stereopsis (Levy \& Lawson, 1978; Ogle \& Wakefield, 1967). This suggests interdependence of the two mechanisms, formalized in a number of models (e.g., Dodwell, 1970; Sperling, 1970). The temporal characteristics of rivalry and stereopsis bear closer scrutiny.

The temporal dependencies of stereopsis are well established. As acknowledged by Wolfe (1983), depth can be perceived from a single flash of less than $150 \mathrm{msec}$. More critically, stereopsis can arise from and be maintained by stimuli that are not simultaneously presented to the eyes. Engel (1970) cites T. Guilloz as first demonstrating, in 1904, that stereoptic depth endured with alternate brief presentation of stereoscopic stimuli (half-images). Ogle (1963) suggested that some form of visual persistence provided simultaneous stimulation at a later stage of the visual system, despite nonsimultaneous stimuli being presented to the retinas. Engel developed this notion (Dodwell \& Engel, 1963; Engel, 1970), and generated a model to explain the temporal characteristics of stereoptic depth perception in terms of the persistence of a central stereoptic mechanism. Providing there was sufficient temporal overlap (by presenting the stereoscopic stimuli either simultaneously or with an interocular delay of less than $100 \mathrm{msec}$ ), Engel found that stereoptic depth would survive quite long binocular dark intervals (on the order of $300 \mathrm{msec}$ ) before re-presentation of the stereoscopic stimuli was necessary. However, for interocular delays between presentation of the stereoscopic half-images of greater than $100 \mathrm{msec}$, depth perception was lost. He interpreted this in terms of a two-stage mechanism, each having different persistence characteristics. The first was a monocular stage with brief persistence (i.e., the stereoscopic half-images needed to be presented with a delay of less than $100 \mathrm{msec}$ for stereopsis to ensue), and the second was a binocular stage with longer persistence (i.e., once stereopsis was established, it would remain with delays of up to $300 \mathrm{msec}$ between restimulation).

It would be of great interest if binocular rivalry had the same differential temporal dependencies between monocular and binocular components as stereopsis. Stereopsis and rivalry have been held by a number of theorists to be intimately associated (Dodwell, 1970; Sperling, 1970), perhaps reflecting facilitatory and inhibitory interactions, respectively, in the same neural mechanism (Bishop, 1973). However, the brief review of work on binocular rivalry with asynchronous presentation establishes two points: that no comparison of the temporal dependencies of binocular rivalry and stereopsis can be made from the literature, and that what has been done has been so unsystematic as to be of limited use for any other purpose. Experiments 1 and 2 go some way towards redressing these deficiencies. ${ }^{1}$ Their aims are as follows: to demonstrate binocular rivalry without simultaneous presentation of the rival stimuli; to explore the temporal dependency of binocular rivalry; and to provide data on those influences and aspects which might prove useful in determining the mechanism by which persistence of rivalry is mediated.

\section{EXPERIMENT 1}

Experiment 1 was designed to explore in a rigorous fashion what we have already casually confirmed in many 
subjects; that binocular rivalry is observed when the leftand right-eye stimuli are only alternately presented. In the procedure, horizontal and vertical gratings were dichoptically presented in a tachistoscope such that when the vertical grating was shown, the other eye was presented with a dark field. After a certain time, this situation was instantaneously reversed, so that the eye originally viewing the vertical grating now viewed a dark field and the other eye now viewed a horizontal grating. The period of time that one field was presented was the same for both horizontal and vertical gratings, and this cycle of asynchronous presentation of horizontal and vertical gratings was repeated for $1 \mathrm{~min}$. A control condition was also tested. Here presentation was synchronous; the two dichoptic gratings were shown simultaneously for a time, and then, for an equivalent time, both eyes viewed a dark field. In this synchronous condition, periods of illumination of both gratings were alternated with the periods of darkness at the same cycle rates as in asynchronous conditions. Thus, total luminous flux integrated over time periods and the number of onsets and offsets of the fields are equivalent for asynchronous and synchronous conditions. These temporal sequences are illustrated graphically in Figure 1. The synchronous condition can also provide information about whether a particular binocular rivalry period initiated by one exposure of the dichoptic stimuli will survive a dark interval until the next exposure of the rival stimuli (cf. Kaufman, 1963).

\section{Method}

Subjects. The subjects were one male (R.O'S.) and two females: D.S., who had had some experience at reporting binocular rivalry but was naive as to the purposes of the experiment, and V.A., who was completely naive as to the phenomenon of binocular rivalry and the purposes of the experiment. V.A. was paid for her services as a subject. All subjects had corrected Snellen acuity of $6 / 6$ or better in each eye, and good stereopsis.

Apparatus. Photographic prints of square-wave gratings were presented in two fields of Gerbrands three-field tachistoscope (T-3B-10). The gratings were mounted on cards such that a circular array of bars, with a diameter of $1 \mathrm{deg}$ of visual angle, was centered in each field. The fundamental spatial frequency of the gratings was 5 cycles (c)/deg of visual angle. The subjects viewed the gratings from $86.4 \mathrm{~cm}$ through pairs of orthogonally oriented polarizing filters, which allowed a vertical grating to be presented to the right eye and a horizontal grating to the left eye, and through appropriate prismatic correction for phoria where necessary. The lights of the tachistoscope were driven by Gerbrands Lamp Drive and Timing circuits (400-3 and 300-6T). The manufacturer specifies that rise and fall times of the tachistoscope lamps are less than $1 \mathrm{msec}$, so periods when a field was illuminated were ideally square-wave pulses. ${ }^{2}$ Luminances were measured through the eyepiece with a Tektronix digital photometer (J16) with narrow-angle light probe (J2523-2). The space average luminance of the gratings was $0.9 \mathrm{~cd} / \mathrm{m}^{2}$ with a contrast of 0.78 . The grating surround had a space average luminance of $0.2 \mathrm{~cd} / \mathrm{m}^{2}$. Concentric with the gratings were four equally spaced, fine, white fusion rings. The inner ring had a diameter of $5.05 \mathrm{deg}$, and the outer a diameter of $6.42 \mathrm{deg}$. Line width of the rings was $0.10 \mathrm{deg}$ of visual angle, and their luminance was $1.6 \mathrm{~cd} / \mathrm{m}^{2}$. The rings, with prismatic correction, permitted all subjects to achieve and maintain binocular alignment throughout the observational sessions. The subjects recorded their ex-
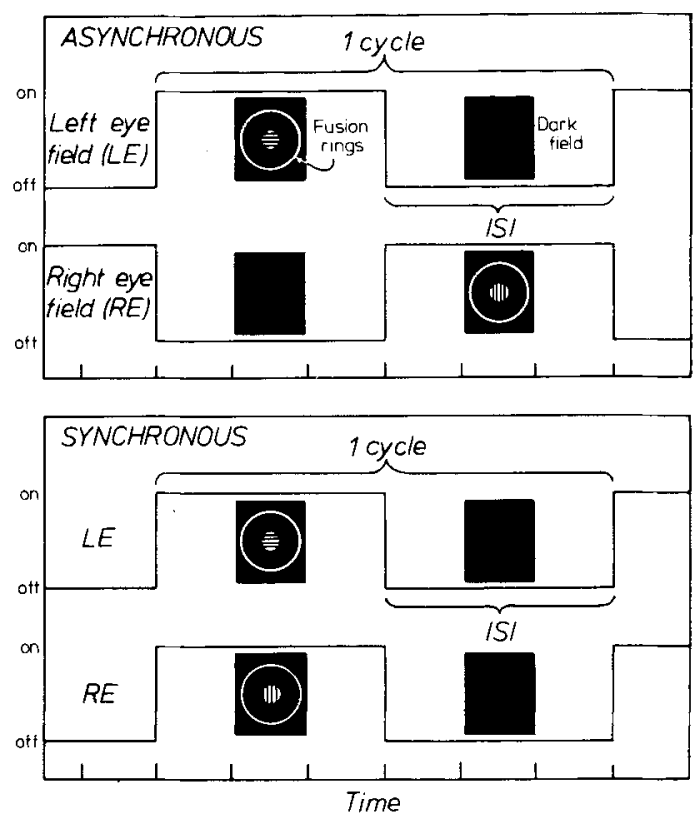

Figure 1. The presentation sequences of the asynchronous and synchronous conditions used. For the asynchronous condition, when one grating was shown, the other eye was shown a dark field. The dark field was replaced by an orthogonal grating at the same time that a dark field replaced the grating in the original eye. One presentation cycle is defined as the events between successive onsets of a grating in one field. The interstimulus interval (ISI) measures the time between offset and onset of a grating in one field. In the corresponding synchronous condition, both gratings were presented simultaneously, followed by a binocular dark field of the same duration. For both conditions, these sequences were repeated for $1 \mathrm{~min}$, during which binocular rivalry was recorded. The stimuli actually presented to the subjects are shown, but not to scale spatially. For the temporal scale, if each tick on the abscissa is taken to be $5 \mathrm{msec}$, then the ISI illustrated equals $15 \mathrm{msec}$. The cycle rate is $33.33 \mathrm{~Hz}$.

perience of binocular rivalry by pressing the left of two buttons for all the time the horizontal orientation was clearly visible (with no trace of the vertical lines) and the right-hand button for all the time the vertical orientation was uniquely present. Neither button was to be pressed when both orientations were visible. Counter timers cumulated the number of presses of each button and the time for which each button was depressed.

Procedure. Each subject completed seven sessions of observations. The sessions were separated by at least $24 \mathrm{~h}$ and lasted for between 1.5 and $2 \mathrm{~h}$. In the first session, the limits of interstimulus intervals (ISIs) that would allow binocular rivalry to be observed were explored. The ISIs were gradually increased, and the naive subjects were encouraged to comment on their perceptions following their recording of binocular rivalry for asynchronous and sychronous presentation.

At some stage in the first session, naive subjects spontaneously discerned flicker and discriminated the separate types of flicker associated with asynchronous and synchronous presentation. It was then revealed by the experimenter that only one of the two types of flicker would be presented on any trial (even when flicker was not noticeable) and that the subjects were required to guess which type of flicker was presented. At the end of the first session, each subject's rivalry rates were plotted against ISI. Eighteen points on the asynchronous function and 20 points on the synchronous function were selected to maximally 
describe the shapes of these functions. In subsequent sessions, all these values of ISI were tested, along with two trials in which there was no stimulus flicker: one with full luminance and another in which the luminance of each field was halved by the addition of neutral density filters.

In Sessions 2 to 7 , all of the above 40 trials were given in completely random order in each session. Each trial consisted of 1 min of binocular rivalry recording, which was initiated by the subject's pressing a third button and terminated by the sound of a bell. Prior to rivalry recording, the naive subjects were required to determine what type of flicker was presented. Feedback was immediately given by the experimenter. All subjects reported if any flicker was noticeable, and V.A. and R.O'S. were required to estimate the brightness of the display using a rating scale with the following anchor points: 0 for total darkness and 100 for the brightness corresponding to that in a display in which both stimuli were presented uninterruptedly (this was demonstrated once at the beginning of each session). Testing was carried out in a quiet laboratory in which the ambient illumination was such that the body of the tachistoscope reflected about $3.7 \mathrm{~cd} / \mathrm{m}^{2}$. The subjects were given $5 \mathrm{~min}$ to adapt to the light levels in the laboratory, and then the trials started. Rest periods of at least $30 \mathrm{sec}$, during which the subject was free to take his/her head from the eyepiece of the tachistoscope, were given between trials. The subjects were encouraged to report anything about their perception that they thought worthy of note. All spontaneous verbalizations were recorded verbatim by the experimenter. In the last session, the subjects were questioned in a nondirective fashion about each trial (e.g., "What were you seeing there?"), and the answers were recorded verbatim.

\section{Results}

Six dependent variables were collected. There were three quantifications of rivalry: rivalry rate, as the total number of buttonpresses per minute; dominance time, as the total time of exclusive visibility of both fields; and mean period. Mean periods were calculated by dividing the total dominance time for one eye-field by the number of times that field was dominant. Averages of mean periods for each eye-field included only those trials in which some rivalry was reported. There were two quantifications of flicker: success at discriminating asynchronous from synchronous flicker was computed, and the number of trials out of six that flicker was evident was simply cumulated. Finally, brightness estimates provided by the subjects were averaged. All variables are treated separately below.

Rate. Rivalry rates have been plotted against ISI and cycle rate for each subject in Figures 2 to 4 . Filled symbols indicate trials on which no flicker was reported. Also included are the rivalry rates for the two conditions in which there was no flicker. Under these graphs are plots of brightness estimates and flicker discrimination. They will be considered below.

Inspection of the graphs supports a number of generalizations about the behavior of binocular rivalry rate as a function of mode of stimulus presentation (asynchronous vs. synchronous) and ISI/cycle rate. With asynchronous presentation, binocular rivalry is observed with cycle rates as slow as about $3 \mathrm{~Hz}$. That means that a stimulus that is not presented to the visual system for $160 \mathrm{msec}$ can suppress, at least occasionally,

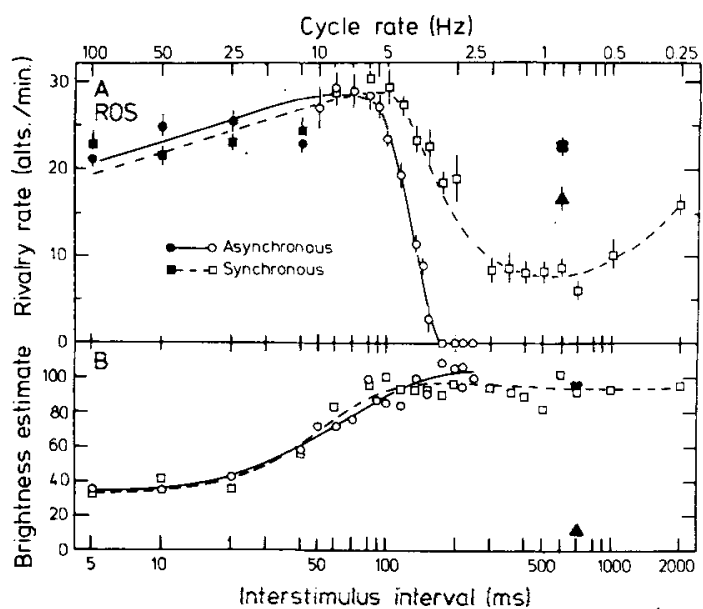

Figure 2. (A) Rivalry rates for asynchronous and synchronous presentation of rival dichoptic stimuli plotted against ISI and cycle rate for R.O'S. Each point is the mean of six trials; vertical bars show standard errors. Unfilled symbols show where flicker was evident in the display. The points indicated by the filled cross and triangle show rivalry rates for continuous presentation of the stimuli at full and half luminance, respectively (their position on the abscissa is meaningless). All curves have been fitted by eye. A $\log$ scale has been used for convenience. (B) Estimated brightness is plotted against ISI and cycle rate for asynchronous and synchronous presentation. Brightness estimates for the two continuously presented stimuli are also shown.

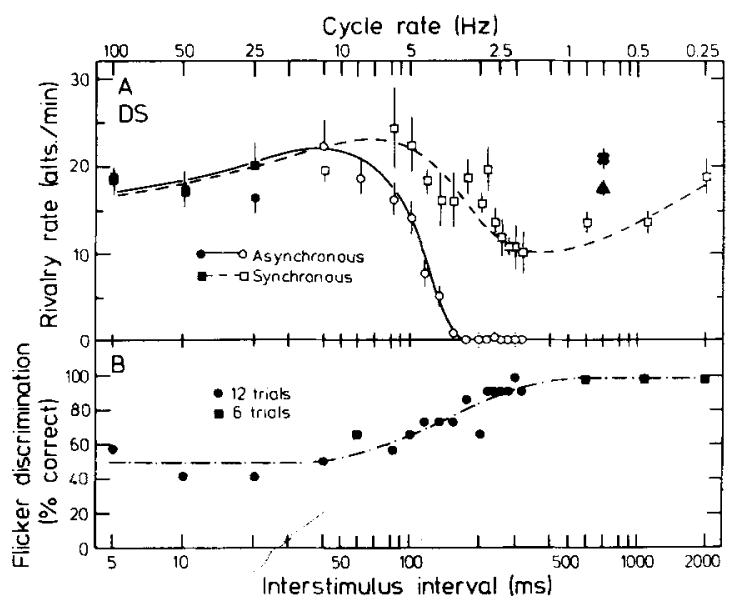

Figure 3. (A) Same as for Figure 2 but for D.S. (B) Percent correct for discrimination of the two types of flicker is plotted against ISI and cycle rate.

a stimulus that is presented for $160 \mathrm{msec}$. At slower cycle rates, each stimulus is seen on each presentation. Quite often, apparent movement of the two stimuli was reported. (Subjects described the two stimuli as "going 'round and 'round" or "going like a washing machine.") While there are individual differences, there is some evidence that binocular rivalry rate is enhanced by flicker, showing a maximum at flicker rates of about $8 \mathrm{~Hz}$ (each stimulus presented for about $40-80 \mathrm{msec}$ ). 


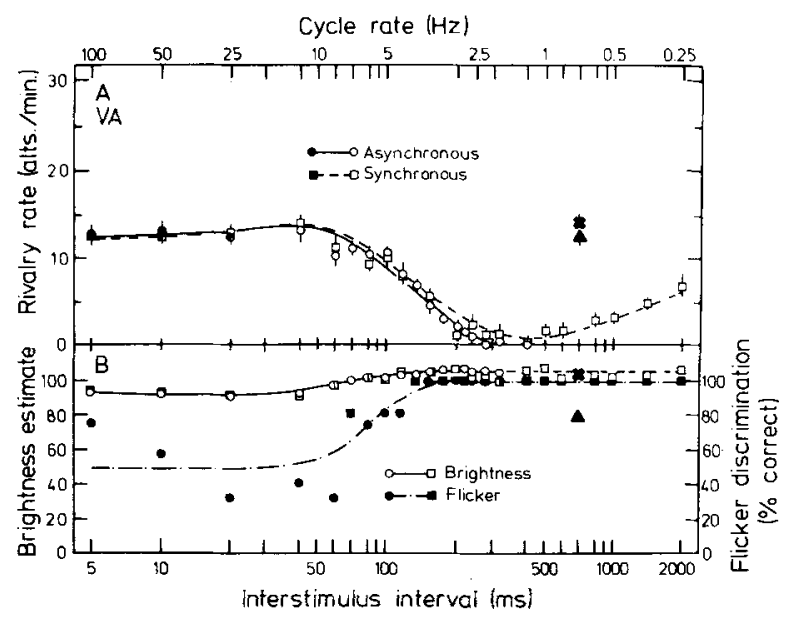

Figure 4. (A) Same as for Figure 2, but for V.A. (B) Both brightness estimates and flicker discrimination are plotted against ISI and cycle rate. For brightness, circles show estimates for asynchronous presentation, squares for synchronous presentation. For flicker, circles show performance over 12 trials, squares over six trials.

For synchronous presentation, binocular rivalry rate is indistinguishable from that for asynchronous presentation from the fastest flicker rate to rates around $8 \mathrm{~Hz}$. At rates down to $1.5 \mathrm{~Hz}$, binocular rivalry lessens, but is never eliminated. At even slower rates, rivalry rate increases again. In these circumstances, the subjects were able to respond to binocular rivalry periods within each separate flash. Both naive subjects spontaneously commented that at the beginning of any flash, both gratings were seen, and that during the course of the exposure, one orientation would eventually come to dominance (cf. Bokander, 1966). Often (for exposures of both stimuli of less than $1 \mathrm{sec}$ ) they complained that offset of the stimuli came before one orientation had reached sufficient dominance to earn a buttonpress.

Flicker. Flicker was noticed for quite fast rates of stimulus alternation. However, a more sensitive indicator of perception of flicker is given by the number of correct discriminations of synchronous and asynchronous flicker. This is because not only were the rival stimuli alternately illuminated, but so were the backing cards on which the stimuli were mounted. Flicker could quite often be discerned in the background while the stimuli seemed to be uninterruptedly presented. Discrimination between the two types of flicker presumably requires that flicker of the stimuli be discerned. Seventyfive percent correct performance was obtained by the two naive subjects at about $5 \mathrm{~Hz}$.

Brightness. At the fastest flicker rates, the stimuli seemed dimmer than when they were presented continuously, but not as dim as when the luminance of the stimuli was objectively halved. Type of flicker does not seem to influence brightness estimates, which increase to an asymptotic level at cycle rates around $3.5 \mathrm{~Hz}$.
Time. Time and period data are graphed together in Figures 5 to 7 . The cumulative time that either grating was dominant has an ISI/cycle-rate function that is essentially the same as that for rate data. Asynchronous and synchronous conditions produce similar cumulative time data from the shortest ISI up to ISIs around 80 to $100 \mathrm{msec}$. For longer ISIs, the asynchronous function falls to 0 at around a $200-\mathrm{msec}$ ISI; although the cumulative dominance time from synchronous presentations decreases, it never reaches 0 . Logically, if ISIs of longer than $2,000 \mathrm{msec}$ (i.e., $2 \mathrm{sec}$ ) were used (e.g., 30 or even $60 \mathrm{sec}$, this last being the same duration as the observation trials used here), then the cumulative time measure would increase.

Period. Mean periods have been averaged only from those eye-field records in which some rivalry was re-

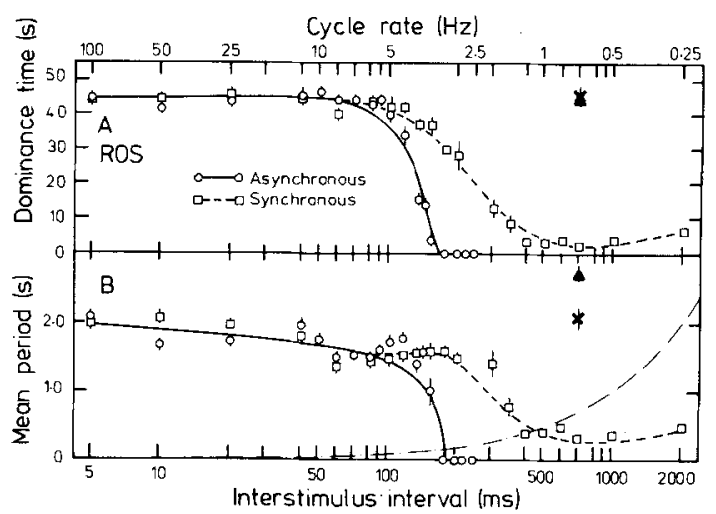

Figure 5. The top graph (A) shows mean dominance time, and synchronous presentation plotted against ISI and cycle rate for R.O'S. Each point is the mean of six trials; vertical bars show for R.O.S. Each point is the mean of six trials; vertical bars show standard errors. The points indicated by the filled cross and triangle show measures for continuous presentation of the stimuli at full and half luminance, respectively (their position on the abscissa is meaningless). All curves have been fitted by eye. A $\log$ scale has been used for convenience. The dotted-anddashed lines in the mean-period graph shows the function of presentation time of the stimuli against ISI.

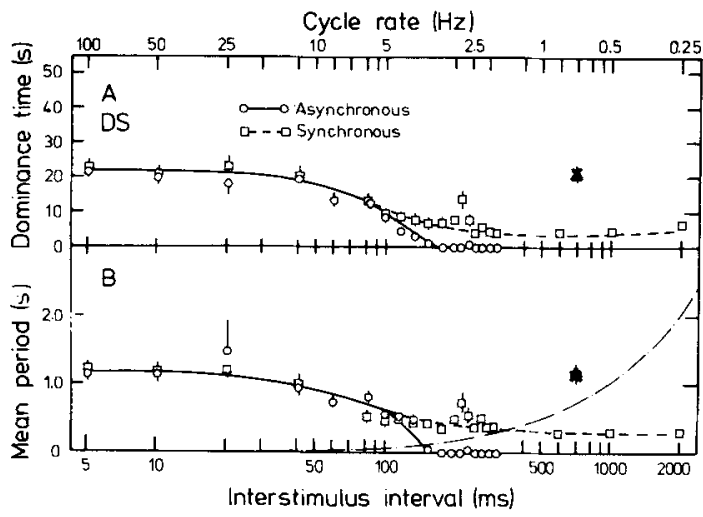

Figure 6. Same as Figure 5 for D.S. 


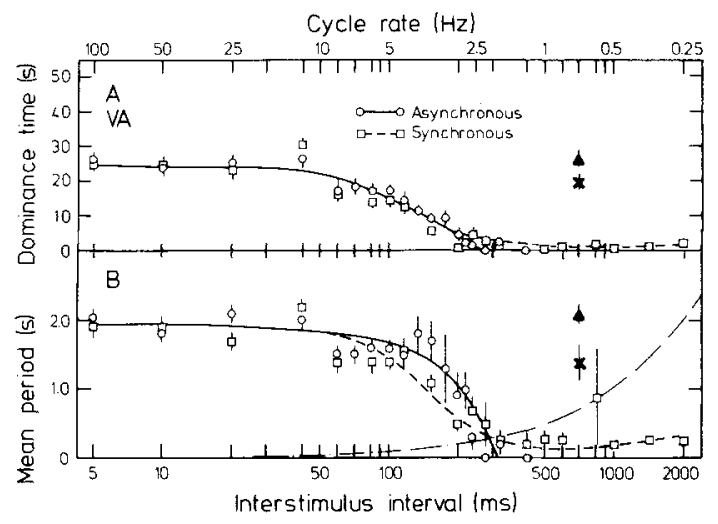

Figure 7. Same as Figure 5 for V.A.

corded. On each graph is also drawn a dotted and dashed line which shows the function if the periods were equal to the duration of individual stimulus presentations, that is, the ISI. It is immediately evident that subjects did not confuse the actual stimulus presentations with binocular rivalry periods, as the data functions do not in any way resemble the above plot. For all three subjects, the periods remain relatively constant as ISI is increased from its shortest value to about 100 msec. Thereafter, periods from asynchronous presentation drop abruptly to zero after a transitional range of ISIs, for which rivalry was observed on some trials but not on others. This range is distinguished by an increase in standard errors for R.O'S. and V.A., but not for D.S., for whom the transitional range was virtually nonexistant. For R.O'S. and D.S., periods for synchronous presentation decrease slightly, then show signs of climbing back to the usual level at the longest ISI. Unlike rate and time data, periods for all subjects were generally shorter than those obtained when the stimuli were simultaneously and uninterruptedly present. Halving the luminance of this condition shortened periods, but only for V.A. did such periods then approximate the periods from intermittent presentation.

Subjects' comments. The subjects made a number of comments, and these are mentioned in the section dealing with the dependent variable they have most bearing on. The subjects often commented on phenomenological differences between adjacent trials, and these are reported only in the following summary: At ISIs at which no flicker is discerned, both rivalry from asynchronous and from synchronous presentation are indistinguishable from normal binocular rivalry. At longer ISIs, when flicker is noticed, naive subjects could not discriminate between asynchronous and synchronous presentation for ISIs up to about $80 \mathrm{msec}$ (about $7 \mathrm{~Hz}$ ). Naive subjects were unable to learn this discrimination in six sessions, despite being given immediate knowledge of the results of their forced choices. For ISIs of 80 to $200 \mathrm{msec}$, with asynchronous presentation, periods of rivalry were interspersed with periods in which both stimuli were seen as moving from one to the other orientation. Synchronous presentation continued to produce conventional rivalry until the dark intervals became clearly evident as an offset of the gratings (at ISIs of between 500 and 1,000 msec). At this stage, the subjects were asked to respond to each individual presentation of the gratings if possible. The subjects commented on the growth of rivalry within each presentation; one grating would take some time to come to dominance.

\section{Discussion}

The results of this experiment show that binocular rivalry occurs when the dichoptic stimuli are never simultaneously presented. At short ISIs, this successive binocular rivalry is indistinguishable from a condition that has an identical number of stimulus onsets and offsets and identical total amount of light per unit time, but provides simultaneous presentation of the rival stimuli (synchronous condition). At ISIs of greater than about $80 \mathrm{msec}$, phenomenal differences emerge between successive and simultaneous rivalry, and successive rivalry breaks down by ISIs of $200 \mathrm{msec}$.

\section{EXPERIMENT 2}

It could be argued that the observation of successive binocular rivalry in Experiment 1 is not surprising. Offset of one stimulus was followed with minimal delay by the onset of the other. Thus, the interaction between the representations of the two stimuli, at whatever site in the visual system where binocular rivalry is initiated, would occur if there were any visual persistence whatever. In other words, if transmission of information about one stimulus was delayed in any part of the visual system prior to the site of binocular rivalry, then the information would arrive simultaneously at that site for a time depending on the magnitude of the transmission lag. Normal binocular rivalry would be observed, because the neural conditions for normal binocular rivalry were being met. This notion can be explored by increasing the interval between offset of one stimulus and onset of the other. An interval should be found, given by the breakdown of binocular rivalry, which exceeds the duration of any monocular visual persistence. This duration can be contrasted with that of a dark interval over which binocular rivalry will survive by central persistence if produced by simultaneous, brief presentation of rival stimuli.

\section{Method}

The subjects, stimuli, and apparatus were the same as those used in Experiment 1. This means that although V.A. was now no longer naive to the phenomenon of binocular rivalry, she was still naive to the purposes of both experiments. The luminance of the fusion rings was $0.3 \mathrm{~cd} / \mathrm{m}^{2}$, and these were presented uninterruptedly. Otherwise, phoric eye movements occurred during the long dark intervals used in this experiment.

Procedure. Again, the overall procedure was the same as that employed in Experiment 1. There were seven sessions, with the first being used to select 12 temporal values to be tested in the following sessions. The dichoptic stimuli were presented for 
5 msec. In asynchronous conditions, after one stimulus was presented, followed by a variable dichoptic ISI, the other stimulus was presented. This cycle was repeated for $1 \mathrm{~min}$. It means that once every $\mathrm{x}$ msec (the dichoptic ISI), a stimulus was presented to the visual system. Once every $2 x+5 \mathrm{msec}$ (the monocular ISI), each eye was stimulated. There were two control conditions. The first was the analogue of the control condition in Experiment 1. To equate total flux per unit time and number of onsets and offsets for an asynchronous trial with a dichoptic ISI of $x$ msec, both stimuli were presented simultaneously, with a gap of $2 x+5$ msec. This will be termed the snychronous 1 condition. The second control condition was designed in recognjtion of the fact that a bright stimulus presented to one eye while a dark field is presented to the other seems as bright as the same bright stimulus viewed binocularly (Levelt, 1968). So a more realistic control of perceived brightness for an asynchronous trial with a dichoptic ISI of $\mathrm{x}$ msec was tested by presenting both stimuli simultaneously followed by a gap of $\mathrm{x}$ msec. This is termed the synchronous 2 condition. It doubles the number of stimulus onsets and offsets and the amount of light per unit time compared with the asynchronous condition, but has the same ISI as the dichoptic ISI of the asynchronous condition. The temporal characteristics of these three conditions are illustrated in Figure 8.

Both naive subjects were required to determine whether any particular trial was an asynchronous or synchronous presenta-

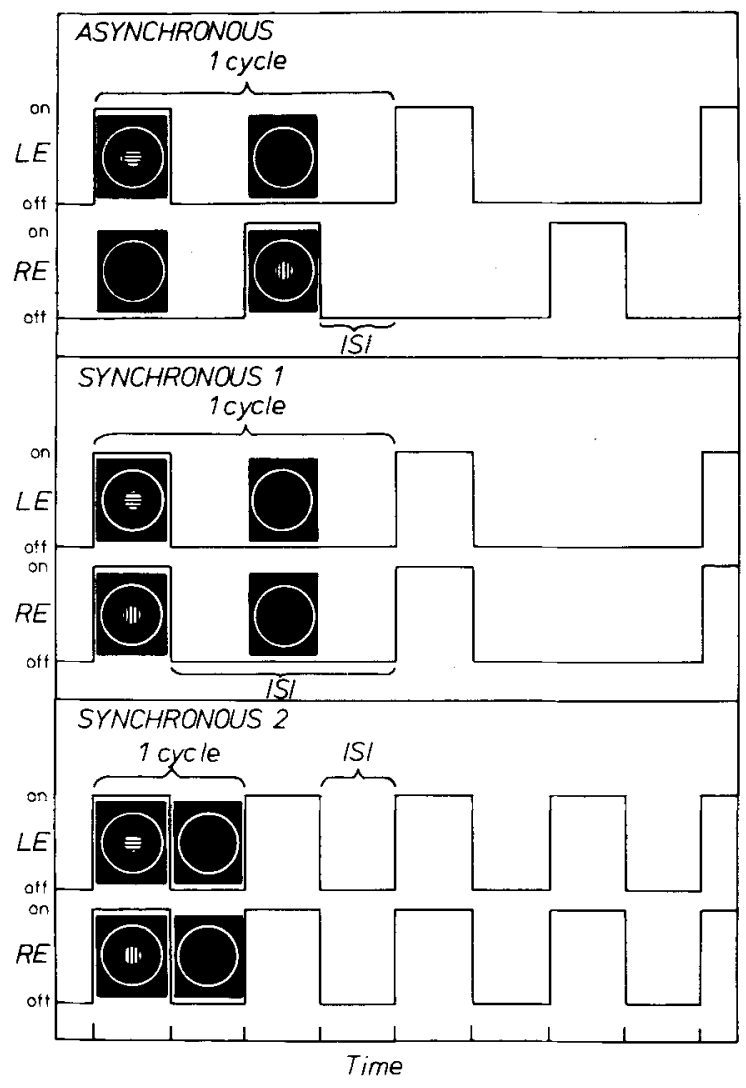

Figure 8. The timing sequences for the three presentation conditions. Stimuli are again not shown to scale spatially. A temporal scale of one tick for each 5 msec means that this example shows an asynchronous presentation with a monocular ISI of $15 \mathrm{msec}$, a dichoptic ISI of $5 \mathrm{msec}$, and a cycle rate of $50 \mathrm{~Hz}$. Synchronous I was used to control for monocular ISI (i.e., $15 \mathrm{msec}$ with a cycle rate of $50 \mathrm{~Hz}$ ); synchronous 2 was used for dichoptic ISI (i.e., $5 \mathrm{msec}$ with a cycle rate of $100 \mathrm{~Hz}$ ). Stimuli were presented for $5 \mathrm{msec}$. tion. Knowledge of results was immediately given by the experimenter. All subjects reported whether flicker was discernible and estimated brightness in the same manner as earlier described. All spontaneous verbalizations were recorded verbatim and naive subjects were again questioned about their hunches as to the experiments' aims. The major difference in the procedure of the two experiments was that the second was carried out in a darkened laboratory (ambient light reflected a luminance of $0.1 \mathrm{~cd} / \mathrm{m}^{2}$ ). Trials were begun after $10 \mathrm{~min}$ of dark adaptation by the subjects. These measures were taken to ensure that the stimuli separated by the longest dark intervals were discernible.

\section{Results}

Rate. Rate data from each subject are plotted against dichoptic ISI for asynchronous presentation and synchronous 2 presentations in Figures 9 to 11. Synchronous 1 data points, which have a dichoptic ISI equal to twice the corresponding asynchronous ISI $+5 \mathrm{msec}$, have been plotted against the values of ISI for which they represent controls. The figures also show brightness and flicker discrimination. A number of features are immediately evident. Binocular rivalry rates for all three presentation conditions decline from maxima at the fastest presentation rates. The synchronous 2 control condition produced higher rivalry rates than did asynchronous presentation. Except at the longest ISIs (of greater than about $100 \mathrm{msec}$ ), binocular rivalry rates produced by asynchronous presentation did not differ appreciably from those of the synchronous 1 control (i.e., ISIs greater than $205 \mathrm{msec}$ ). The absolute limit for the perception of binocular rivalry without simultaneous presentation seems to be at cycle rates of about $3 \mathrm{~Hz}$, as in Experiment 1. This is despite the fact that, in Experiment 2, onset of one stimulus came $160 \mathrm{msec}$ after the offset of a 5-msec flash of the other stimulus, and that each eye was "refreshed" by a new presentation of the 5-msec flash only once every $325 \mathrm{msec}$.

For Subjects R.O'S. and D.S., there is a noticeable divergence of the asynchronous and synchronous functions at a dichoptic ISI of about $100 \mathrm{msec}$. Rivalry rates for asynchronous presentation drop to 0 for dichoptic ISIs of about $200 \mathrm{msec}$, whereas there is still appreciable rivalry with synchronous presentation rates separated by ISIs greater than $300 \mathrm{msec}$.

Flicker. Flicker was discernible for ISIs greater than about $20 \mathrm{msec}$. The two types of flicker (asynchronous vs. synchronous) were not, however, discriminable by the naive subjects for cycle rates of less than $5 \mathrm{~Hz}$, and the discrimination was not learned in six sessions despite the provision of immediate knowledge of results (see subjects' comments).

Brightness. As ISIs increased, the estimated brightness of the stimuli decreased. For all subjects, the synchronous 2 condition was judged to be brighter than the two other conditions. Thus, it seems that some brightness summation (Sherrington, 1904) did occur. The synchronous 1 brightness function was very similar to that for asynchronous presentation, suggesting that it is the more appropriate control for brightness.

Time. Time and period data are plotted for each subject in Figures 12 to 14. As ISIs increased, cumulative 


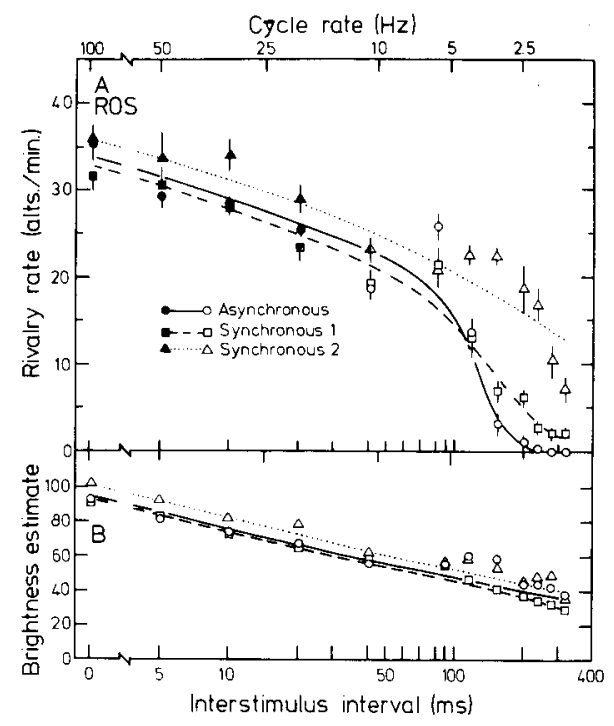

Figure 9. (A) Rivalry rates for asynchronous and synchronous 1 and 2 presentations plotted against ISI and cycle rate for R.O'S. Each point is the mean of six trials; vertical bars show standard errors. Unfilled symbols show where flicker was evident in the display. All curves have been fitted by eye. A log scale has been used for convenience. (B) Estimated brightness plotted against ISI and cycle rate for asynchronous and synchronous 1 and 2 presentations.

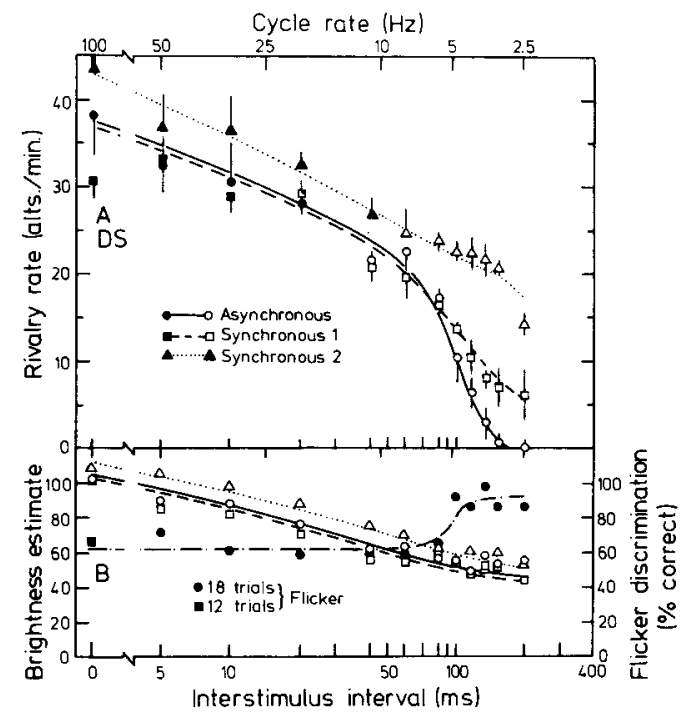

Figure 10. (A) Same as Figure 9 but for D.S. (B) Estimated brightness plotted against ISI and cycle rate for asynchronous and synchronous 1 and 2 presentations with unfilled symbols. Filled symbols show percent correct in flicker discrimination.

time of dominance increased slightly for R.O'S. and V.A. and stayed relatively constant for D.S. up to dichoptic ISIs of $50 \mathrm{msec}$. At longer ISIs, cumulative times decreased to 0 , this being more rapid for asynchronous presentation (R.O'S. and D.S.).

Period. The ISI functions of period data resemble those found for time data, with the exception that period length became very variable at long ISIs.
Subjects' comments. The naive subjects made occasional comments about the appearance of the binocular rivalry, again with reference to the differences between adjacent trials. It seemed to one of us (R.O'S.), as a subject, that at the longest ISIs, the stimuli were so faint that the rivalry became more akin to fluctuations of threshold stimuli (Guilford, 1927). However, both naive subjects said that the rivalry they experienced at these long ISIs was "real rivalry." Certainly, the brisker rivalry reported with synchronous presentation at the longest ISIs was not phenomenally different from the asynchronous conditions for which they were controls. These subjects occasionally gave descriptions similar

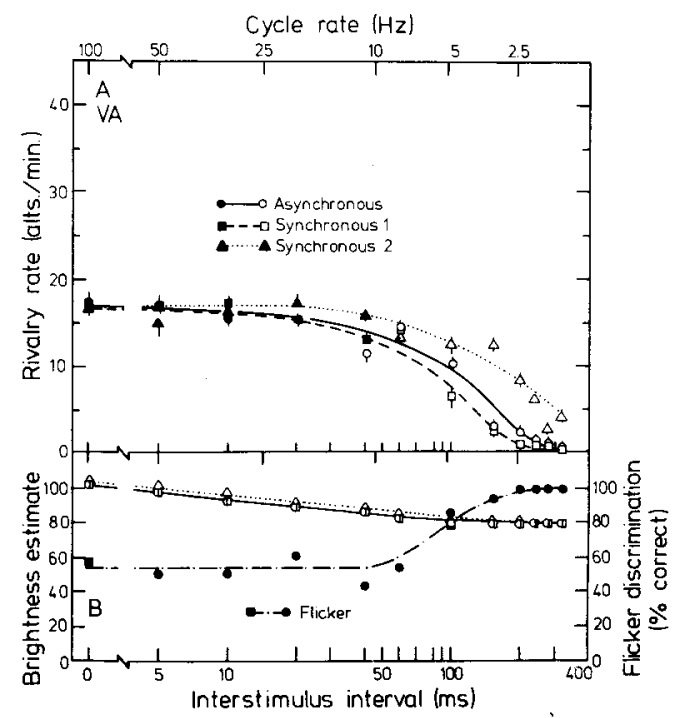

Figure 11. (A) Same as Figure 9, but for V.A. (B) Same as Figure 10, but for V.A.

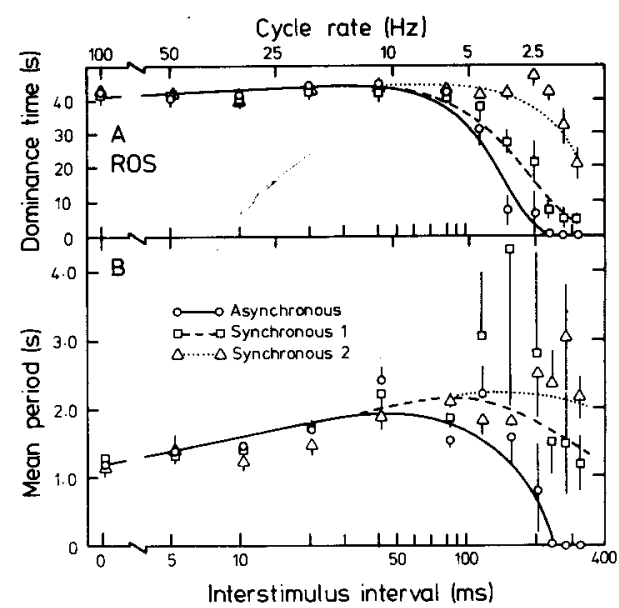

Figure 12. The top graph (A) shows mean dominance time, and the bottom graph (B) shows mean period for asynchronous and synchronous 1 and 2 presentations, plotted against ISI and cycle rate for R.O'S. Each point is the mean of six trials; vertical bars show'standard errors. All curves have been fitted by eye. A log scale has been used for convenience. 


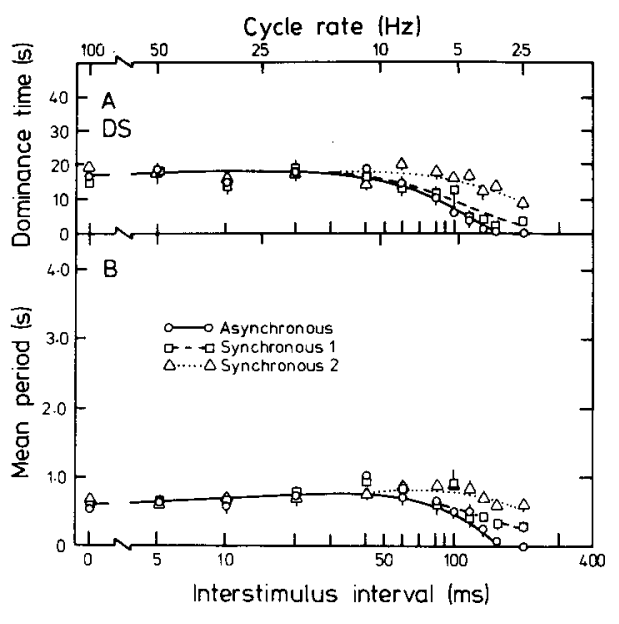

Figure 13. Same as Figure 12, but for D.S.

to those of abnormal fusion (Wolfe, 1983), alternating with periods of rivalry (e.g., "Checks; they start to change a little bit, then it goes off"; and "Crisscrossed, but changing all the time").

The naive subjects were asked if they realized that there were more examples of synchronous flicker in Experiment 2 than in Experiment 1. V.A. correctly estimated that there were twice as many examples of synchronous presentation. D.S. realized in the third session that there were more synchronous trials, and thereafter, whenever she was uncertain, she said "synchronous." This accounts for her generally elevated performance over the whole ISI range.

D.S., being a reasonably experienced subject, believed what she was told about the experiments' aims. V.A., however, suspected that the purpose was to compare light and dark adaptation in Experiments 1 and 2, respectively.

\section{Discussion}

This experiment shows that binocular rivalry can occur between one stimulus presented to one eye for

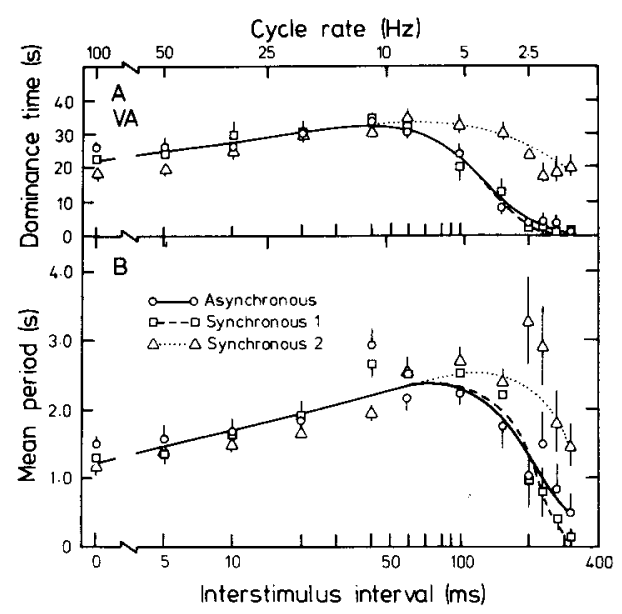

Figure 14. Same as Figure 12, but for V.A. only $5 \mathrm{msec}$ and another presented to the other eye for $5 \mathrm{msec}$, even when the offset of one stimulus occurs $100 \mathrm{msec}$ prior to the onset of the other. The rivalry is indistinguishable from normal rivalry at high cycle rates at which flicker is not discerned. However, at cycle rates that allow flicker to be noticed, the three rivalry measures of rate, time, and period, the apparent luminance of the stimuli, and the appearance of the flicker are all similar for asynchronous presentation and an appropriate synchronous control for cycle rates up to about $5 \mathrm{~Hz}$. Although the shapes of the various functions differ between Experiments 1 and 2, they show similar results in terms of the limits of the asynchronous cycle rates that allow rivalry to be perceived and to be discriminated from control conditions. Taken together, Experiments 1 and 2 demonstrate unequivocally that binocular rivalry can occur without simultaneous presentation of the dichoptic rival stimuli.

The difference between the shapes of the three functions for each rivalry measure reflects two aspects. First, the difference between synchronous 2 and synchronous 1 is illusory, as they are really parts of the same synchronous function plotted on different scales (the former on a monocular and the latter on a dichoptic ISI scale). They were plotted separately in that they acted as controls for monocular and dichoptic ISI. However, the synchronous 2 condition could be shifted to the left by ISI plus 5 msec, and it would then become part of the synchronous 1 function, which would consist of 24 instead of 12 data points.

The second aspect of the difference between the functions is more theoretically important. For subjects R.O'S. and D.S., there was a separation of the asynchronous and synchronous functions at dichoptic ISIs greater than $100 \mathrm{msec}$, which implicates central visual persistence in rivalry. (It is not clear why V.A. did not show this separation of the two functions, but it is suggestive that her rivalry rate was considerably lower than that of the other two subjects.) Rivalry with asynchronous presentation relies on monocular persistence's being long enough for simultaneous neural representations of the rival stimuli to converge on the central rivalry mechanism. Thus, the dichoptic ISI has to be less than the duration of monocular persistence (of about $100 \mathrm{msec}$ ). However, with synchronous presentation, the rivalry mechanism is triggered by simultaneous stimuli. The fact that the rivalry mechanism does not need to be "refreshed" for about $300 \mathrm{msec}$ while still producing appreciable rivalry suggests a different time course of central persistence. This confirms other work done on binocular interaction with stereoptic stimuli (Engel, 1970).

\section{GENERAL DISCUSSION}

The results of Experiments 1 and 2 show quite clearly that binocular rivalry can occur without simultaneous presentation of rival stimuli. No models of binocular rivalry directly address its dependence on the temporal 
characteristics of the rival stimuli (see O'Shea, 1983, for a comprehensive review of rivalry theories; Dodwell, 1970, Fox \& Rasche, 1969, Levelt, 1968, McDougall, 1906, and Sperling, 1970 give the sources of some of the major models). Some have speculated on the temporal nature of the units mooted to underlie binocular rivalry (e.g., transient vs. sustained cells; Hollins, 1980), but these models have been tested only indirectly. However, it is possible to stimulate two different populations of units by using different rates of flicker (e.g., sustained units at very slow or very fast flicker rates and transient units at intermediate rates), and these experiments have shown that it is feasible to do so. Nevertheless, the preservation of rivalry across a wide range of ISIs suggests that the rival interactions within sustained and transient units are similar. The duration of the interval between the dichoptic stimuli (see Experiment 2), however, seemed to be more important than the fact that the stimuli were flickering at a particular rate. It would be possible to uncouple these two temporal parameters by keeping ISI constant but changing flicker rate (by altering the duration that the stimulus was physically presented), or vice versa.

The similarity of binocular rivalry to stereopsis in its tolerance of dichoptic ISIs (Engel, 1970) is intriguing. The limit of about $100 \mathrm{msec}$ for binocular interactions seems ubiquitous. A stimulus presented to one eye will interact with another presented within $100 \mathrm{msec}$ to the other eye, to produce binocular summation (Thorn \& Boynton, 1974), metacontrast and masking effects (Weisstein, 1971), stereopsis (Dodwell \& Engel, 1963), and now rivalry. Binocular summation and interocular transfer of masking have been explained in terms of involvement of binocular units (Blake, Sloane, \& Fox, 1981, and Breitmeyer \& Ganz, 1976, respectively), which are also held to account for stereopsis and rivalry (e.g., Bishop, 1973). Subjects expected to lack such binocular units, because of congenital strabismus, do not show binocular summation (Williams, 1974), interocular transfer of adaptation effects ${ }^{3}$ (Banks, Aslin, \& Letson, 1975), or stereopsis, and show rivalry which seems different in character to that of normals (Schor, 1977; Smith, Levi, Harwerth, \& White, 1982).

Development of a model relating all the above phenomena would be far beyond the scope of this paper, and certainly more easily said than done. Difficulties include the demonstration of dichoptic spatial masking (Levi, Harwerth, \& Smith, 1979) and temporal frequency masking (Levi, Pass, \& Manny, 1981) in stereoblind observers, and that interocular transfer of adaptation effects is independent of rivalry (O'Shea \& Crassini, 1981; Wade \& Wenderoth, 1978). Nevertheless, there are models relating rivalry and stereopsis (Dodwell, 1970; Sperling, 1970). Dodwell's contribution grew out of his attempt to add rivalry phenomena to a model of stereopsis which allowed interactions between dichoptic, temporally disparate stimuli dependent on short-term monocular persistence $(100 \mathrm{msec})$ and was capable of long-term, central, stereoptic persistence $(300 \mathrm{msec})$ (Dodwell \& Engel, 1963). The fact that rivalry shows the same temporal dependencies is strong circumstantial evidence that rivalry and stereopsis are interdependent. It is not inconceivable that the rivalry mechanism and the stereoptic mechanism share common input pathways or involve the same units.

\section{REFERENCES}

Alexanden, K. R., \& Berman, M. S. (1976, December). The effect of intermittent alternating visual stimulation on binocular rivalry. Paper presented to the American Academy of Optometry, Portland, OR.

Anderson, J. D., Bechtoldt, H. P., \& Dunlap, G. L. (1978). Binocular integration in line rivalry. Bulletin of the Psychonomic Society, 11, 399-403.

Banks, M. S., Aslin, R. N., \& Letson, R. D. (1975). Sensitive period for the development of human binocular vision. Science, 190, 675-677.

Bishop, P. O. (1973). Neurophysiology of binocular single vision and stereopsis. In R. Jung (Ed.), Handbook of sensory physiology (Vol. 7). Berlin: Springer-Verlag.

Blake, R., \& Conmack, R. H. (1979). On utrocular discrimination. Perception \& Psychophysics, 26, 53-68.

Blake, R., Sloane, M., \& Fox, R. (1981). Further developments in binocular summation. Perception \& Psychophysics, 30, 266-276.

BoKAnder, I. (1966). The importance of collative-affective and intensive arousal potential in stereoscopically induced conflict. Scandinavian Journal of Psychology, 7, 234-238.

Bowen, T. G. R., \& Haley, L. T. (1964). Temporal effects in binocular vision. Psychonomic Science, 1, 409-410.

Breitmeyer, B. G., \& Ganz, L. (1976). Implications of sustained and transient channels for theories of visual pattern masking, saccadic suppression, and information processing. Psychological Review, 83, 1-36.

Clarke, P. G. H. (1977). Subjective standstill caused by the interaction of moving patterns. Vision Research, 17, 1243.

Dawson, S. (1915-1917). The experimental study of binocular colour mixture. British Journal of Psychology, 8, 510-551.

Dodweld, P. C. (1970). Visual pattern recognition. New York: Holt, Rinehart \& Winston.

Dodwell, P. C., \& ENGel, G. R. (1963). A theory of binocular fusion. Nature, 198, 39-40, 73-74.

ENGEL, G. R. (1970). An investigation of visual responses to brief stereoscopic stimuli. Quarterly Journal of Experimental Psychology, 22, 148-166.

Fox, R., \& Rasche, F, (1969). Binocular rivalry and reciprocal inhibition. Perception \& Psychophysics, 5, 215-217.

Goldstein, A. G. (1970). Binocular fusion and contour suppression. Perception \& Psychophysics, 7, 28-32.

Guilford, J. P. (1927). Fluctuations of attention with weak stimuli. American Journal of Psychology, 38, 534-583.

Hoches RG, J. (1964). Depth perception loss with local monocular suppression: A problem in the explanation of stereopsis. Science, 145, 1334-1335.

Hochberg, J. (1965). Stereopsis suppression: Addendum. Science, 146,800 .

Hollins, M. (1980). The effect of contrast on the completeness of binocular rivalry suppression. Perception \& Psychophysics, 27, 550-556.

KaUfman, L. (1963). On the spread of suppression and binocular rivalry. Vision Research, 3, 401-415.

KLïver, H. (1926). An experimental study of the eidetic type Genetic Psychology Monographs, 1(2), 70-229.

LEVELT, W. J. M. (1968). On binocular rivalry. Soesterberg, The Netherlands: Institute for Perception. 
Levi, D. M., Haqwerth, R. S., \& Smith, E. L. (1979). Humans deprived of normal binocular vision have binocular interactions tuned to size and orientation. Science, 206, 852-854.

Levi, D. M., Pass, A. S., \& Manny, R. E. (1981). Binocular interactions in normal and anomalous binocular vision: Effects of flicker. British Journal of Opthalmology, 66, 57-63.

Levy, M. M., \& Lawson, R. B. (1978). Stereopsis and binocular rivalry from dichoptic stereograms. Vision Research, 18, 239-246

McDougall, W. (1906). The physiological factors of the attention process. Mind, 15, 329-359.

Mollon, J. D., \& Polden, P. G. (1978). On the time constants of tachistoscopes. Quarterly Journal of Experimental Psychology, 30, 555-568.

OGLE, K. N. (1963). Stereoscopic depth perception and exposure delay between images to the two eyes. Journal of the Optical Society of America, 53, 1296-1304.

Ogle, K. N., \& Wakefield, J. M. (1967). Stereoscopic depth and binocular rivalry. Vision Research, 7, 89-98.

O'She A, R. P. (1983). Spatial and temporal determinants of binocular contour rivalry. Unpublished doctoral dissertation, University of Queensland, Australia.

O'Shea, R. P., \& Crassini, B. (1981). Interocular transfer of the motion after-effect is not reduced by binocular rivalry. Vision Research, 21, 801-804.

Riggs, L. A., Volkmann, F. C., \& Moore, R. K. (1981). Suppression of the blackout due to blinks. Vision Research, 21, 1075-1079.

Schor, C. M. (1977). Visual stimuli for strabismic suppression. Perception, 6, 583-593.

Sherrington, C. S. (1904). On binocular flicker and the correlation of activity of corresponding retinal points. British Journal of Psychology, 1, 26-60.

Smith, E. L., III, Levi, D. M., Hahwerth, R. S., \& White, J. M. (1982). On the relationship between binocular rivalry and strabismic suppression. Unpublished paper from College of Optometry, University of Houston.

Sperling, G. (1970). Binocular vision: A physical and neural theory. American Journal of Psychology, 83, 461-534.

Stromeyer, C. F., III (1970). Eidetikers. Psychology Today, 4, 76-80.

Thorn, F., \& Boynton, R. M. (1974). Human binocular summation at absolute threshold. Vision Research, 14, 445-458.

WADE, N. J., \& WENDEROTH, P. (1978). The influence of colour and contour rivalry on the magnitude of the tilt after-effect. Vision Research, 18, 827-835.

WALKen, P. (1978). Binocular rivalry: Central or peripheral selective processes? Psychological Bulletin, 85, 376-389.

Weisstein, N. (1971). W-shaped and U-shaped functions obtained for monoptic and dichoptic disk-disk masking. Perception \& Psychophysics, 9, 275-278.

Werner, H. (1940). Studies in contour: Strobostereoscopic phenomena. American Journal of Psychology, 53, 418-422.
Wheatstone, C. (1852). Contributions to the physiology of vision-Part the first. On some remarkable, and hither to unobserved, phaenomena of binocular vision. Philosophical Magazine and Journal of Science, 3, 241-267.

Williams, R. (1974). The effect of strabismus on dichoptic summation of form information. Vision Research, 14, 307-309.

WoLFE, J. M. (1983). Influence of spatial frequency, luminance, and duration on binocular rivalry and abnormal fusion of briefly presented dichoptic stimuli. Perception, 12, 447-456.

\section{NOTES}

1. However, the crucial experiment to link the temporal dependencies of rivalry and stereopsis is not reported here. It would require that rivalry and stereopsis be measured in a factorial design formed by the crossing of a range of variations of interocular delay between presentations of the dichoptic stimuli, and a range of intraocular delays (analogous to the design of Engel, 1970). The results for stereopsis should be similar to those found by Engel. Rivalry, on the other hand, presents some methodological and interpretive difficulties. Rivalry is not as easy to measure as stereopsis which can be judged quickly; each rivalry datum requires $1 \mathrm{~min}$ to gather. Also, stereopsis has an all-or-nothing character, either there is depth or there is not, whereas rivalry measures can vary over a range from no rivalry (fusion) to rapid alternations (e.g., 60 alternations/min). This would prevent the easy comparison of rivalry and stereopsis as implied in the above design.

2. Mollon and Polden (1978) have shown that the time for which visible light is emitted from some tachistoscope lamps is far greater than implied by manufacturers. Whether this is as perceptually important as claimed is not clear. The light remaining after the notional pulse is emitted is of much lower intensity and decays to zero usually within $20 \mathrm{msec}$. Any stimulus so illuminated may be effectively invisible through masking by its being previously strongly illuminated. It is also not clear to what extent the combination of Gerbrands circuits and Sylvania F4T5/CWX lamps, as used in Experiments 1 and 2, suffer from this problem, because these were not tested by Mollon and Polden. If a worst performance of 20 -msec persistence is assumed for Sylvania lamps, then this may influence the results of Experiment 1 but not of Experiment 2, which used quite long delays between offset of one stimulus and onset of the next.

3. To our knowledge, interocular transfer of masking and metacontrast over a range of temporal asynchronies has not been tested in stereoblind observers.

(Manuscript received October 21, 1983; revision accepted for publication June 22,1984 .) 